\title{
Effect of Changes in Hydraulic Conductivity on Exit Gradient at Selected Levee Systems Using Numerical Models
}

\author{
Fred T. Tracy ${ }^{1, *}$ and Maureen K. Corcoran ${ }^{2}$ \\ ${ }^{1}$ US Army Engineer Research and Development Center, Information Technology Laboratory, Vicksburg, MS, USA \\ ${ }^{2}$ US Army Engineer Research and Development Center, Geotechnical and Structures Laboratory, Vicksburg, MS, USA
}

\begin{abstract}
The objective of the research was to provide a better understanding of the influence of hydraulic conductivity on the exit gradient for a rectangular block representing a root zone. A critical area of concern to design engineers is the exit gradient at the toe of the levee and other sensitive areas. If the exit gradient becomes too large, water flows too fast, thus creating the potential for piping and internal erosion. Seepage analyses using the finite element method were conducted where the hydraulic conductivity $k$ within an estimated root zone was varied. These analyses were based on the assumption that a root system alters the $k$ of a soil. Levee systems used in this study were located in Sacramento, CA; Burlington, WA; Albuquerque, NM; and Portland, OR. These sites were selected based on available data from previous investigations. Both two-dimensional (2-D) steady-state and transient computations were made. Three-dimensional (3-D) solutions were generated by extruding the 2-D cross sections from each study site to form a 3-D mesh and then running a parallel program. For each levee cross section, a root zone was placed at different locations on the levee profile. The root zone was estimated from geophysical surveys to be approximately $1.8 \mathrm{~m} \times 1.5 \mathrm{~m}$ in size. The original $(k)$ assigned to the root zone was multiplied by a factor, $\beta, 0.01 \leq \beta \leq 100$. The 2 -D computations were made with values of $\beta=0.01,1$, and 100 for the different root zone locations. Exit gradients calculated for root zones placed at the bottom of the dewatered drainage ditch in Albuquerque, NM, and on and just beyond the toe of the levee in the other levee systems showed changes in exit gradients when $k$ was varied. At other locations of the root zone along the levee, exit gradient showed small or no change with different values of $k$. Field measurements were not a part of this study.
\end{abstract}

Keywords: Exit gradient, seepage in levees, vegetation modeling, piping, finite element method, numerical models of levees, steady-state seepage, transient seepage.

\section{EXIT GRADIENT}

Exit gradient at the toe of a levee system is one of the most important design quantities that a practicing engineer uses. Flow in the soil of the levee is governed by a total head or potential $(\varphi)$ similar to that of electromagnetic forces. The vertical component of gradient $(i)$ is defined by

$i=-\frac{\partial \varphi}{\partial y}$

where $y$ is the vertical coordinate. The negative sign is used to have positive values. The critical vertical exit gradient at the toe of the levee and at the bottom of a drainage ditch is computed by

$i_{c}=\frac{\gamma_{S S}}{\gamma_{w}}-1$

where $i_{c}$ is the critical vertical exit gradient, $\gamma_{s s}$ is the density of saturated soil, and $\gamma_{w}$ is the density of water.

The allowable factor of safety for use in the design of seepage control measures should correspond to a maximum vertical exit gradient at the toe of 0.5 [1].

*Address correspondence to this author at the U.S. Army Engineer Research and Development Center, Information Technology Laboratory, 3909 Halls Ferry Road, Vicksburg, MS 39180-6199, USA; Tel: 601-634-4112;

Fax: 601-634-2324; E-mail: Fred.T.Tracy@usace.army.mil

\section{PREVIOUS WORK ON ROOT SYSTEMS MODEL- ING}

\subsection{Ways of Modeling Roots in Soil}

One way to merge the movement of water through soil and plant root systems is the Soil-Plant-Atmosphere Continuum (SPAC) model [2]. Pore spaces between the soil particles are filled with water and air, and hydraulic conductivity allows the formation of analogous structures for water movement in both soil and plants.

The Root-Soil Water Modeling system (R-SWMS) [3] is one example where roots are modeled along the edges of a three-dimensional (3-D) finite element mesh. The focus of R-SWMS is on detailed simulation of water flow in heterogeneous, unsaturated soils with plants. The plant root architecture is described in 3-D as a series of connected nodes and the water uptake is modeled based on the water potential difference between soil and root. Consequently, the water fluxes within the root system are also determined at each root node. A 3-D finite element mesh surrounds the root geometry description. R-SWMS is also capable of simulating solute transport and root growth. This computer code was built from previous work by Simunek et al. [4], Doussan et al. [5], and Somma et al. [6]. 


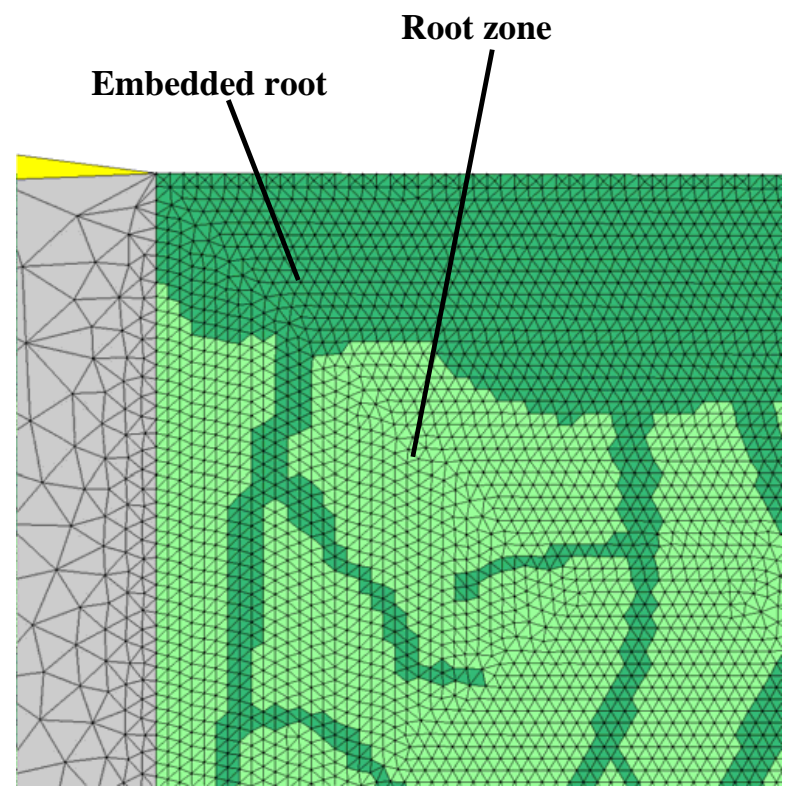

Fig. (1). Roots embedded into the finite element mesh.

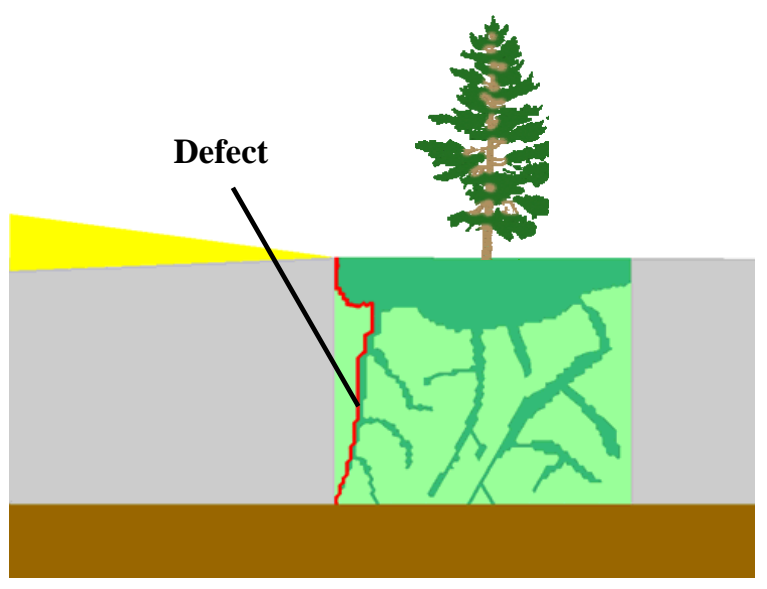

Fig. (2). Root zone with roots and a defect.

HYDRUS [7] takes a different approach. In a finite element mesh, an area in 2-D or volume in 3-D is designated as a plant-root zone, and a root distribution function describing the density of the root system is defined.

Another approach to a root-zone model [8] is to embed an actual root into a triangular (2-D) or prism (3-D) mesh with the roots as a part of the finite element mesh representing the soil but having a different hydraulic conductivity (see Fig. 1). The root zone is filled with small finite elements of approximately $2.5 \mathrm{~cm}$ in each dimension, and a root consists of finite elements in the mesh instead of line segments connecting nodes of the mesh. The advantage of this method is that defects (see Fig. 2) caused by the root can be easily represented.

Another approach is to assume a random distribution of macropore heterogeneities in the root zone creating large variations in hydraulic conductivity in the small elements of the root zone [9]. Each small finite element in the root zone has a distinct value of hydraulic conductivity. However, this approach is very computer intensive.

The last approach is to assume a constant hydraulic conductivity inside a root zone, although typically altered by the roots from its original value. This is the simplest approach but it works well for regional studies which is the focus of this current research. Specifically, the effect of woody vegetation on exit gradient evaluated on the land side of the levee systems is determined using this modeling approach.

\subsection{Equations for the SPAC Model [2]}

Horizontal water flow in soil is modeled by Darcy's Law as

$u=-\left(\frac{k}{\gamma_{w}}\right) \frac{\partial p}{\partial x}$

where $u$ is the seepage velocity (volume or water per unit area per unit time) of water in the horizontal or $x$ direction, $k$ is the hydraulic conductivity of the soil, $\gamma_{w}$ is the density of water, and $p$ is the pore pressure. The plant equation for flow starts with the concept of the Hagen-Poiseuille equation [8] representing flow in a pipe, That is,

$Q=\left(\pi R^{2}\right) u=-\left(\frac{\pi R^{4}}{8 \mu}\right) \frac{\partial p}{\partial x}$

where $Q$ is the flow per unit time in the pipe, $R$ is the radius of the pipe, and $\mu$ is the viscosity of water. Thus, by dividing Eq. 3 by Eq. 4, the hydraulic conductivity of a single pipe, $k_{\text {pipe }}$, can be thought of as

$k_{\text {pipe }}=\frac{\gamma_{\mathrm{w}} R^{2}}{8 \mu}$

Because a root contains capillaries of many different radii, the flow in a root is the sum of all $N$ individual capillaries and is as follows:

$Q=\sum_{i=1}^{N}\left(\pi R_{\mathrm{i}}^{2}\right) u=-\sum_{i=1}^{N}\left(\frac{\pi R_{i}^{4}}{8 \mu}\right) \frac{\partial p}{\partial x}$

This gives the longitudinal hydraulic conductivity for flow of water in the root as

$k_{\text {root }, L}=\frac{\gamma_{w} \sum_{i=1}^{\mathrm{N}} R_{i}^{4}}{8 \mu \sum_{i=1}^{\mathrm{N}} R_{i}^{2}}$

A transverse hydraulic conductivity $\left(k_{\text {root }, T}\right)$ representing flow from the soil to inside the root can also be measured and used in a numerical model. This is illustrated by the defects from roots shown in Fig. (2).

\section{OBJECTIVE AND PROCEDURE}

The objective of the research was to provide a better understanding of the influence of woody vegetation on levees on underseepage and, specifically, the exit gradient at key design points on levees. This was done by numerically placing different nearly rectangular root zones at various locations on a levee and on four different levee systems (Figs. 3, 11, 16, and 21) and performing seepage analyses using the finite element method. Hydraulic conductivity $k$ within each root zone was then varied to establish an upper and lower bound of exit gradient. Once changed from the original 


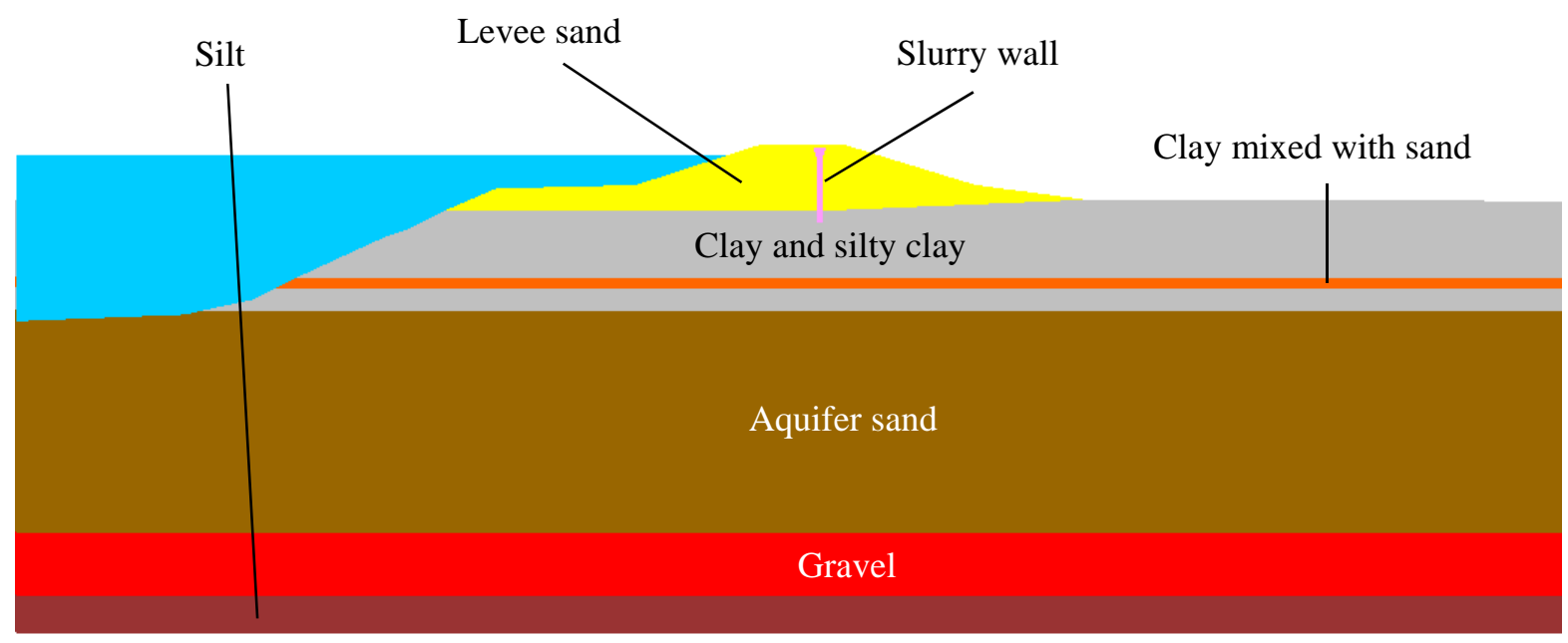

Fig. (3). 2-D cross section of Sacramento, CA, levee.

value, hydraulic conductivity was considered constant inside the root zone. These analyses were based on the assumption that a root system alters the $k$ of a soil. A levee cross section for each levee system was entered into the Groundwater Modeling System (GMS) [10] for these analyses. Both twodimensional (2-D) steady-state and transient computations were made using Seep2D [11]. GMS is a graphical user interface for groundwater analyses using 2-D and 3-D finite element and finite difference programs. Seep2D is one of the 2-D finite element programs. The interface allows the user to interactively define geometry and boundary conditions, generate the mesh, compute results, and display the results. Three-dimensional solutions were generated by extruding the 2-D cross sections to form a 3-D mesh and then running a parallel 3-D groundwater program using high performance computing. The 3-D root zone was estimated from geophysical surveys to be approximately $1.8 \mathrm{~m} \times 1.8 \mathrm{~m} \times 1.5 \mathrm{~m}$ in size [8]. The 2-D root zone was estimated as $1.8 \mathrm{~m} \times 1.5 \mathrm{~m}$ per linear foot of levee. Generating the 3-D data was automated and the results were computed from a parallel research program, so in the 3-D case, GMS was only used to visualize the results.

The original hydraulic conductivity assigned to the root zone was multiplied by a factor, $\beta$, as follows:

$k_{\text {veg }}=\beta k_{\text {orig }}$

where $k_{v e g}$ is the modified hydraulic conductivity, $\beta$ is a positive parameter with values of $0.01 \leq \beta \leq 100$, and $k_{\text {orig }}$ is the original hydraulic conductivity without a root in the zone. It was determined from field experiments [8] that these values of $\beta$ were sufficient to bound the results. The use of $\beta$ allows the computation of a range of key variables, such as exit gradient and pore pressure, for different soil conditions inside the root zone and also compare these variables with the case where there is no woody vegetation $(\beta=$ 1). Seep2D was run with values of $\beta=0.01,1$, and 100 for the different root zone locations. $\beta$ has values both greater than 1 and less than 1 because both situations can exist. If preferred paths are created, then $\beta>1$. However, if the dense roots form a barrier to flow, then $\beta<1$. As a part of this research, a transient version of Seep2D was written so that both steady-state and transient computations could be made.

\section{DESCRIPTION OF LEVEE SYSTEM FINITE ELE- MENT MODELS, RESULTS, AND ANALYSES}

A finite element mesh for each levee system was generated from the riverside of the levee to the levee and then to $609.6 \mathrm{~m}$ from the levee on the land side in the horizontal direction and vertically downward, until an impervious bottom was found. The boundary condition on the river side was constant total head corresponding to the river elevation, and the boundary condition on the vertical land side (609.6 $\mathrm{m}$ from the toe of levee) was total head with a value of the elevation of the land surface. The top boundary on the land side was a phreatic surface boundary condition, where a nonlinear iteration was done in the finite element solution to find the final position of the phreatic surface. Thousands of 2-D finite elements were used in the solution for each levee (many more than actually needed) to ensure accuracy of results. Further, a convergence test was done for the Sacramento levee, where the mesh was refined and results from the original solution and refined solution were compared. The percentage differences for gradient in these calculations were $3.8 \%$ or lower, which is certainly acceptable. Each levee system is discussed in the following sections.

\subsection{Sacramento, $\mathrm{CA}$}

\subsubsection{Finite Element Model}

Fig. (3) shows the cross section from the Sacramento levee along the Sacramento River for the Sacramento, CA, levee with the different soil layers, and Fig. (4) shows a portion of the finite element mesh. The levee is sand with a slurry wall, and the root systems are in clay and silty clay substratums. Table 1 gives the hydraulic conductivities used for the soil layers. $k_{H}$ is the hydraulic conductivity in the horizontal direction, and $k_{V}$ is the hydraulic conductivity in the 


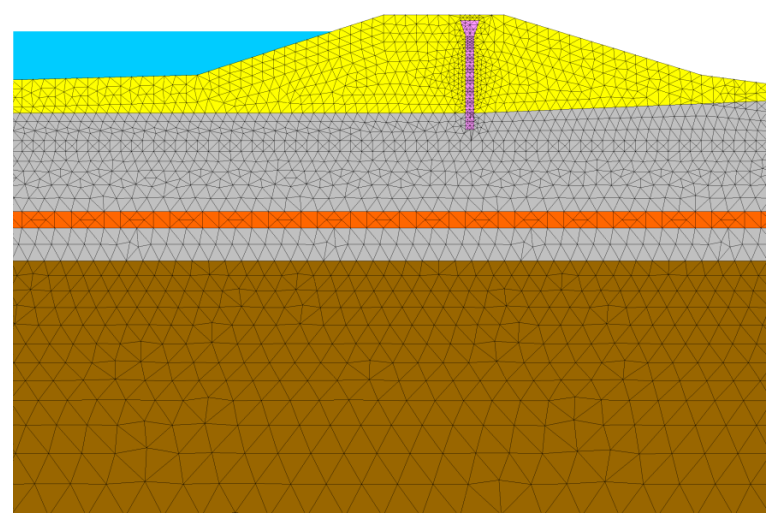

Fig. (4). Portion of 2-D finite element mesh for Sacramento, CA, levee.

Table 1. Original hydraulic conductivities $(\mathrm{cm} / \mathrm{sec})$ for soils without roots used in model for Sacramento, CA.

\begin{tabular}{|c|c|c|}
\hline Material & $\boldsymbol{k}_{H}(\mathbf{c m} / \mathbf{s e c})$ & $\boldsymbol{k}_{V}(\mathbf{c m} / \mathbf{s e c})$ \\
\hline \hline Levee sand & $8.00 \times 10^{-3}$ & $2.00 \times 10^{-3}$ \\
\hline Clay and silty clay & $8.00 \times 10^{-4}$ & $2.00 \times 10^{-4}$ \\
\hline Clay mixed with sand & $3.00 \times 10^{-5}$ & $1.00 \times 10^{-5}$ \\
\hline Aquifer sand & $8.00 \times 10^{-2}$ & $2.00 \times 10^{-2}$ \\
\hline Gravel & $2.00 \times 10^{-2}$ & $2.00 \times 10^{-2}$ \\
\hline Silt & $1.00 \times 10^{-4}$ & $1.00 \times 10^{-4}$ \\
\hline Slurry wall & $1.00 \times 10^{-6}$ & $1.00 \times 10^{-6}$ \\
\hline
\end{tabular}

vertical direction. Fig. (5) shows the placement of the root zones on the levee. Each of these root zones will be activated in succession and results computed from the respective modified root zones and compared with results when the root zone has its original state. The crest of the levee is at $9.75 \mathrm{~m}$, and the elevation of the river was set to $7.01 \mathrm{~m}, 7.92 \mathrm{~m}$, and $8.84 \mathrm{~m}$ for steady-state flow analyses. The elevation of the water level on the land side was set to $3.66 \mathrm{~m}$ at a distance of $609.6 \mathrm{~m}$ landward of the levee. For the transient analysis, the hydrograph shown in Fig. (6) was used. The water level shown in blue is a typical water level at the crest of a flood.

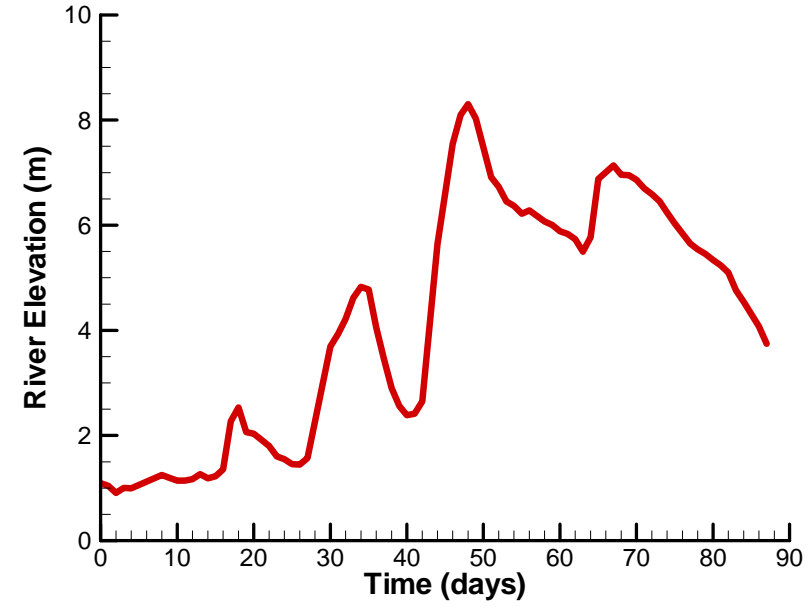

Fig. (6). Portion of hydrograph for 1986 flood on Sacramento River.

\subsubsection{Results and Analysis}

Table 2 gives steady-state values of exit gradient at the toe for values of $\beta$ for the root zone placements for the Sacramento levee for the river elevations of $7.92 \mathrm{~m}$ and $8.84 \mathrm{~m}$. Transient results for when the river rises to $7.92 \mathrm{~m}$ are also given. Fig. (7) shows the phreatic surface just at the beginning of the transient analysis, and Fig, (8) shows the phreatic surface when the river reached $7.92 \mathrm{~m}$.

The root zone placed just beyond the toe of the levee shows the most variation in the exit gradient at the toe, and the root zone on the toe of the levee has the second most variation as $\beta$ was varied (Table 2). Root zone placements at the other locations on the levee had minimal effect on the exit gradient at the toe as also shown in Table 2. For the root zone just beyond the toe of the levee, as $\beta$ was increased, the exit gradient at the toe decreased, because the root zone acts as a drain and very little head loss occurs in a drain. Conversely, as $\beta$ was decreased, the exit gradient at the toe increased. This is understood by noting that a less pervious region than the surrounding soil acts like a confining layer, and more head loss occurs in this case.

The root zone on the toe of the levee caused the exit gradient at the toe to be smaller for both $\beta=0.01$ and $\beta=100$ compared to $\beta=1$. To understand this phenomenon,

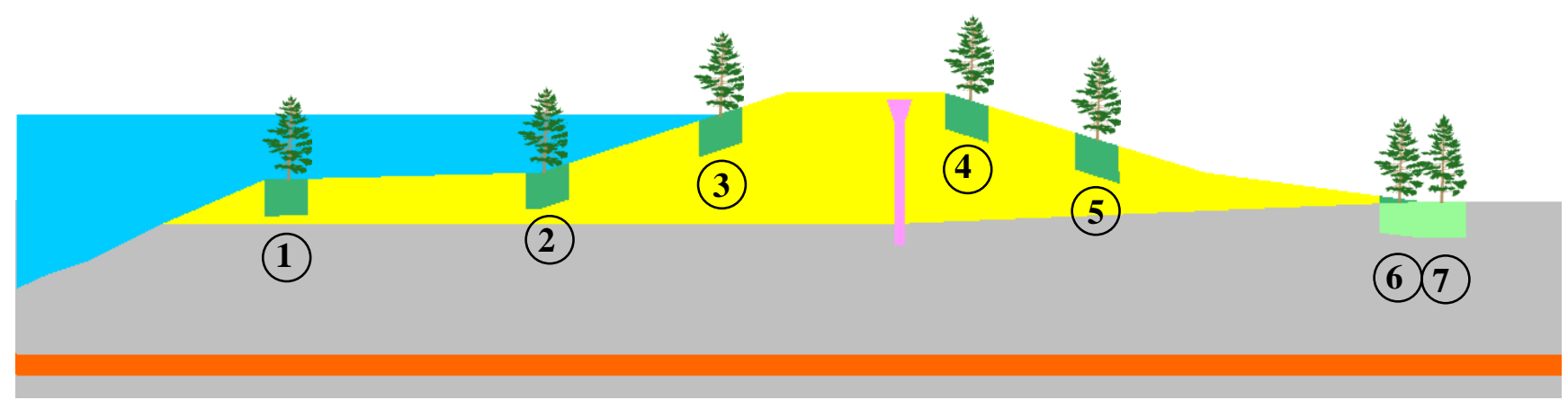

Fig. (5). Root zone placement for Sacramento, CA, levee. 


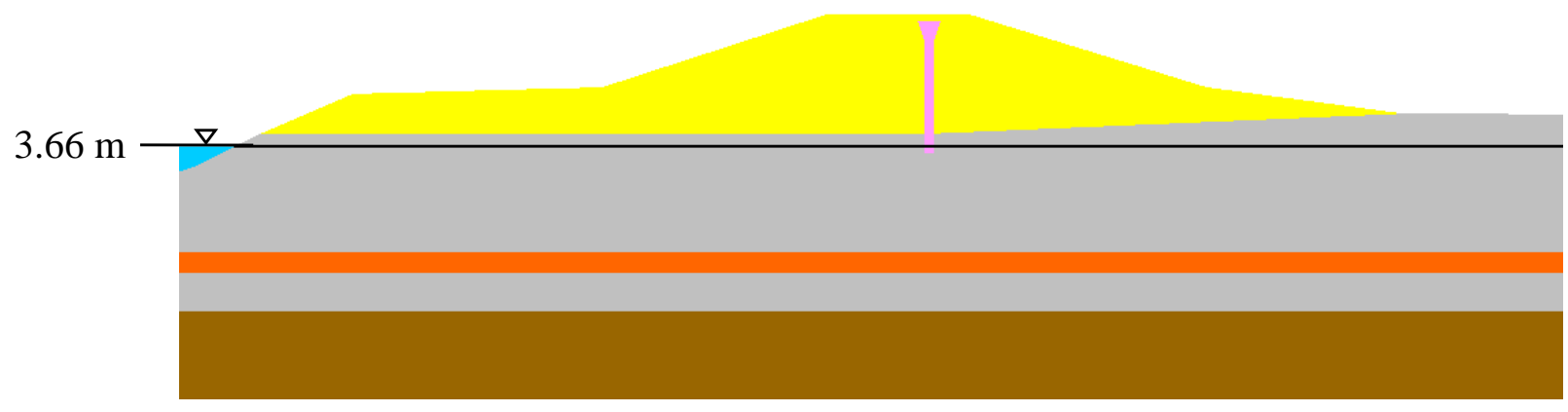

Fig. (7). Initial position of phreatic surface for transient solution for Sacramento, CA, levee.

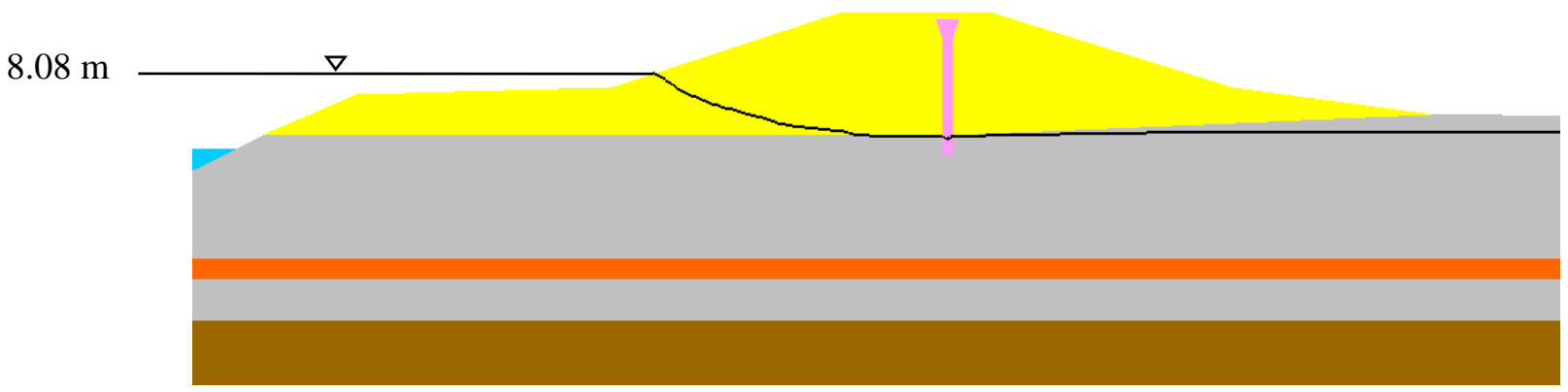

Fig. (8). Portion of phreatic surface at the maximum flood stage from transient solution for Sacramento, CA, levee.

Table 2. Exit gradient calculated for different root zone locations using three different value of $\beta$.

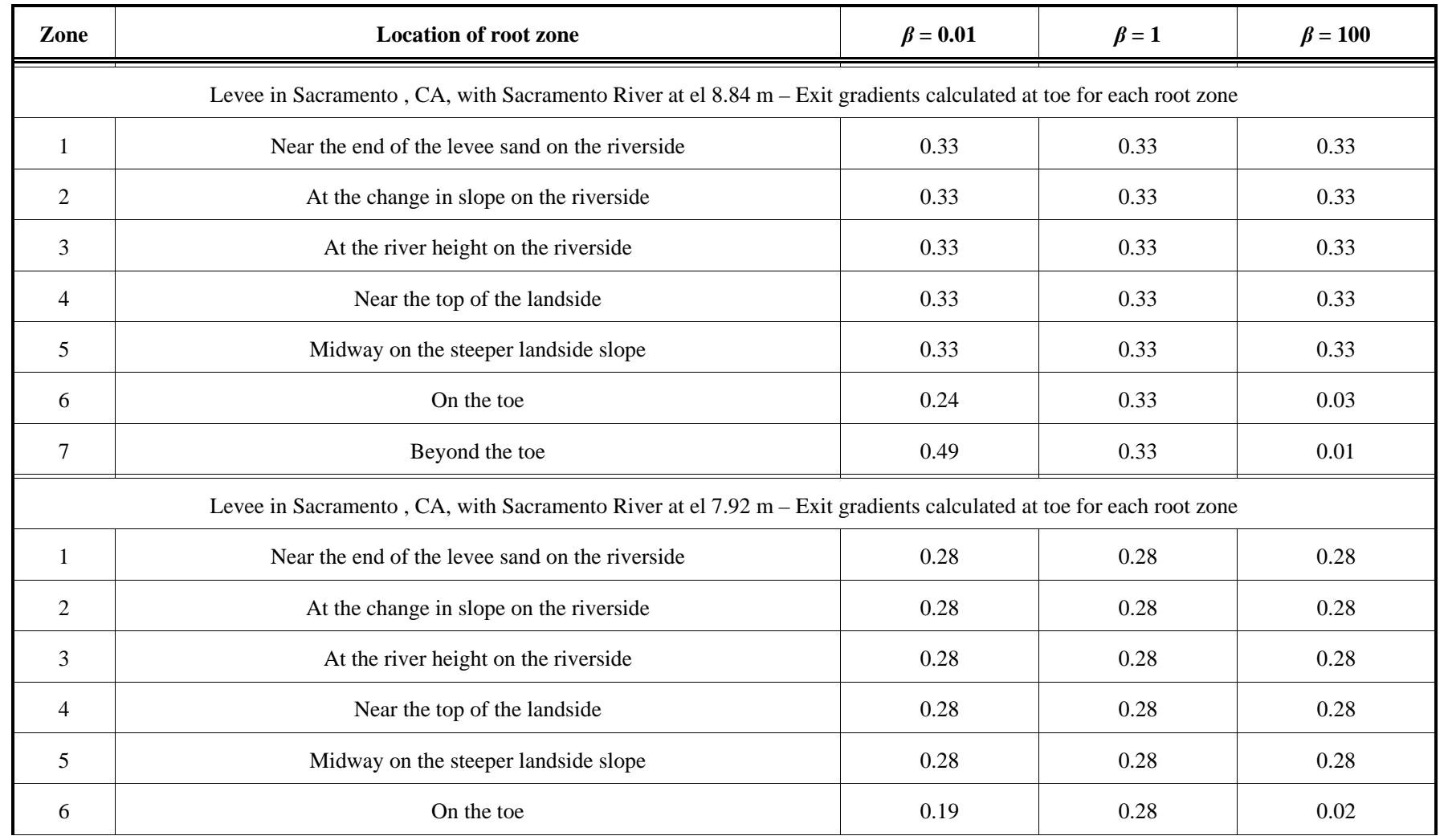


Table 2.. contd...

\begin{tabular}{|c|c|c|c|c|}
\hline Zone & Location of root zone & $\beta=0.01$ & $\beta=1$ & $\beta=100$ \\
\hline 7 & Beyond the toe & 0.43 & 0.28 & 0.00 \\
\hline \multicolumn{5}{|c|}{ Levee in Burlington, WA, with Skagit River at el $11.80 \mathrm{~m}$ - Exit gradients calculated at toe for each root zone } \\
\hline $1 \mathrm{a}$ & Beyond the toe & 1.09 & 0.81 & 0.11 \\
\hline 2 & On the toe & 0.59 & 0.81 & 0.22 \\
\hline 3 & Nearly halfway to the top of the levee on the landside & 0.81 & 0.81 & 0.81 \\
\hline 4 & Nearly halfway to the top of the levee on the riverside & 0.80 & 0.81 & 0.82 \\
\hline 1a & Beyond the lower toe & 0.84 & 0.69 & 0.11 \\
\hline $1 \mathrm{~b}$ & Beyond the lower toe - Transient & 0.64 & 0.53 & 0.13 \\
\hline 2 & Just beyond the upper toe of the levee & 0.68 & 0.69 & 0.69 \\
\hline 3 & Nearly halfway to the top of the levee on the riverside & 0.69 & 0.69 & 0.69 \\
\hline 4 & At the water level on the riverside & 0.68 & 0.69 & 0.69 \\
\hline \multicolumn{5}{|c|}{ Levee in Albuquerque, NM, with Rio Grande River at el $1521.56 \mathrm{~m}$ - Exit gradients calculated at bottom of dewatered drainage ditch for each root zo } \\
\hline 1 & Near the toe & 1.00 & 0.99 & 0.99 \\
\hline \multicolumn{5}{|c|}{ Levee in Albuquerque, NM, with Rio Grande River at el $1520.65 \mathrm{~m}$ - Exit gradients calculated at bottom of dewatered drainage ditch for each root zo } \\
\hline $2 b$ & At the bottom of the ditch - Transient & 0.85 & 0.74 & 0.12 \\
\hline
\end{tabular}

consider Fig. (9) showing the $5.5 \mathrm{~m}$ equipotential line for the case where the river elevation was $8.84 \mathrm{~m}$. The exit gradient at the toe for a given $\beta$ is approximated by

$i_{e} \approx-\frac{\Delta \varphi}{\Delta y}=\frac{5.5 \mathrm{~m}-5.2 \mathrm{~m}}{\mathrm{y}_{\mathrm{A}}-\mathrm{y}_{\mathrm{B}}}=\frac{0.3 \mathrm{~m}}{\mathrm{y}_{\mathrm{A}}-\mathrm{y}_{\mathrm{B}}}$

where $\Delta \varphi$ is an increment of total head, $\Delta y$ is an increment of $y, y_{A}$ is the $y$ coordinate of Point $\mathrm{A}$, and $y_{B}$ is the $y$ coordinate of Point B. When $\beta$ went from 1 to 0.01 , the $\varphi=5.5$ $\mathrm{m}$ contour line moved closer to the ground surface on the left edge of the root zone. However, equipotential lines are refracted by

$\frac{\tan \theta_{1}}{\tan \theta_{2}}=\frac{k_{1}}{k_{2}}$

for a homogeneous medium, where $\theta_{1}$ and $\theta_{2}$ are the respective angles an equipotential line makes with the interface between two soils having hydraulic conductivities, $k_{1}$ and $k_{2}$, respectively (Fig. 10). For example, if $\theta_{1}=45$ degrees, then $\tan \theta_{2}=0.01$, causing $\theta_{2}$ to be very small. The contour line is therefore bent downward through the root zone and causes $y_{A}-y_{B}$ to be longer for $\beta=0.01$ as compared to $\beta=1$. The longer $y_{A}-y_{B}$ is, the smaller the exit gradient (Eq. 9).

For the case when $\beta=100, y_{A}-y_{B}$ is somewhat longer that for the case when $\beta=1$, so the exit gradient is again reduced.

The exit gradients for the lower elevation of the river are less than those at higher elevations. Finally, all exit gradients are below the 0.5 limit regardless of the existence of a root zone.

For the transient solution, the exit gradients are less than the steady-state values for the same river elevation. The phreatic surface near the river side was climbing mostly through highly pervious levee sand, so there was little lag in the phreatic surface as the water level increased. As will be seen in the analyses of the other levee sites, there will often be significant lag in the phreatic surface. 


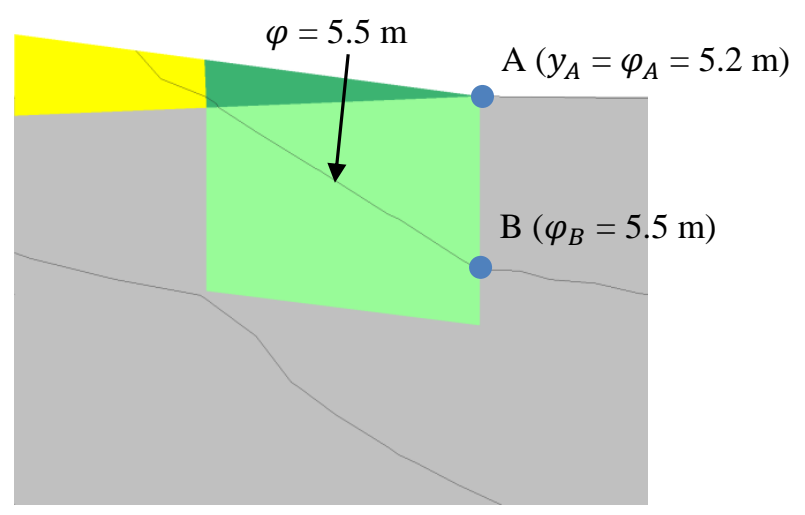

(a) $\beta=0.01$

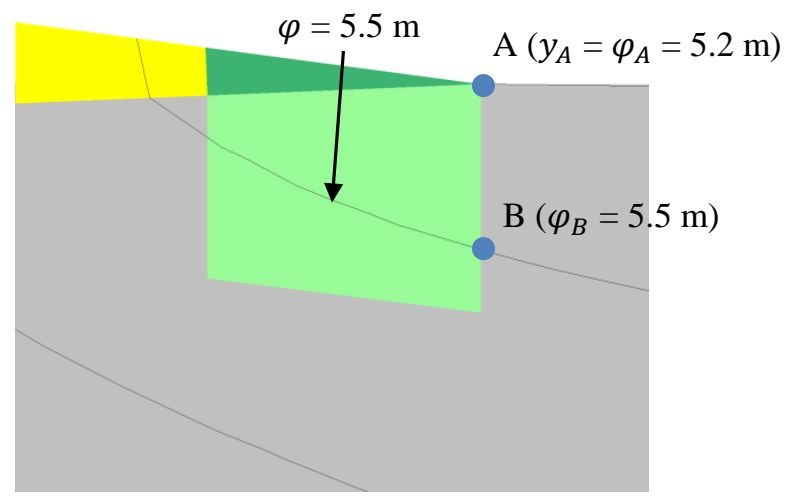

(b) $\beta=1$

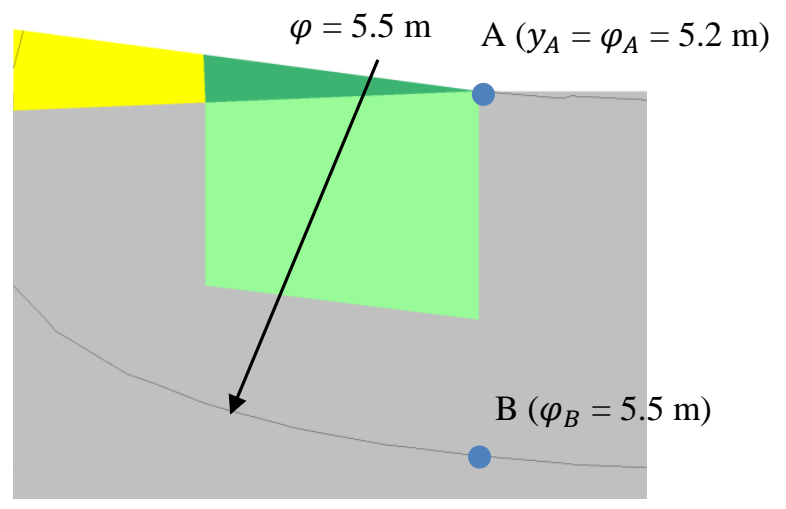

(c) $\beta=100$

Fig. (9). Equipotential line, $\psi=5.5 \mathrm{~m}$, for three values of $\ell$ for root zone on toe of levee.

\subsection{Burlington, WA}

\subsubsection{Finite Element Model}

Fig. (11) shows the cross section for the levee along the Skagit River in Burlington, WA, and the root zone placements on the levee. The levee is silty sand with root

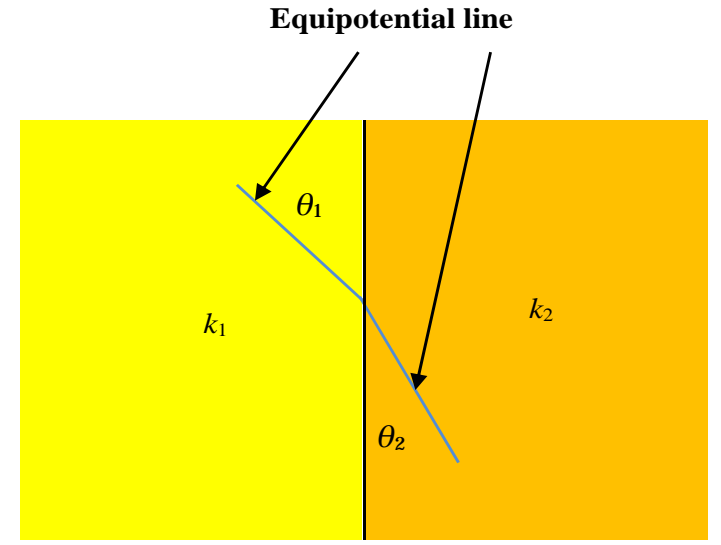

Fig. (10). Equipotential line refracted by interface between two soils with different hydraulic conductivity.

Table 3. Original hydraulic conductivities $(\mathrm{cm} / \mathrm{sec})$ for soils without roots used in model for Burlington, WA.

\begin{tabular}{|c|c|c|}
\hline Material & $\boldsymbol{k}_{\boldsymbol{H}}(\mathbf{c m} / \mathbf{s e c})$ & $\boldsymbol{k}_{V}(\mathbf{c m} / \mathbf{s e c})$ \\
\hline \hline Silty sand & $1.17 \times 10^{-3}$ & $1.17 \times 10^{-3}$ \\
\hline Silt & $2.00 \times 10^{-3}$ & $1.00 \times 10^{-3}$ \\
\hline Sand & $4.00 \times 10^{-2}$ & $4.00 \times 10^{-2}$ \\
\hline
\end{tabular}

zones within the levee and in the substratum of silt. A portion of the finite element mesh is shown in Fig. (12). The elevation of the river for steady-state analysis was set to $11.80 \mathrm{~m}$, which is the highest stage from the 1995 flood on the hydrograph used in the transient analysis as shown in Fig. (13). The elevation of the water level on the landside was set to $9.81 \mathrm{~m}$. Table 3 shows the hydraulic conductivities for this cross sect.

\subsubsection{Results and Analysis}

Table 2 gives exit gradient at the toe of the levee resulting from varying $\beta$ and the root zone locations. Fig. (14) shows the river elevation and phreatic surface at the beginning of the transient run, and Fig. (15) shows this information when the flood has crested at $11.80 \mathrm{~m}$. The results for this levee are very similar to those of the Sacramento levee in the sense that exit gradients given in Table $\mathbf{2}$ are changed by varying values of $\beta$ significantly at the toe of the levee and just beyond the toe of the levee. However, significant differences from the Sacramento levee are that many of the exit gradients are greater than the 0.5 value, and for the transient solution, the phreatic surface lags somewhat as the flood level rises.

\subsection{Portland, OR}

\subsubsection{Finite Element Model}

The geometry, tree placement, and soil layers for the levee along the Columbia River in Portland, OR, are shown in 


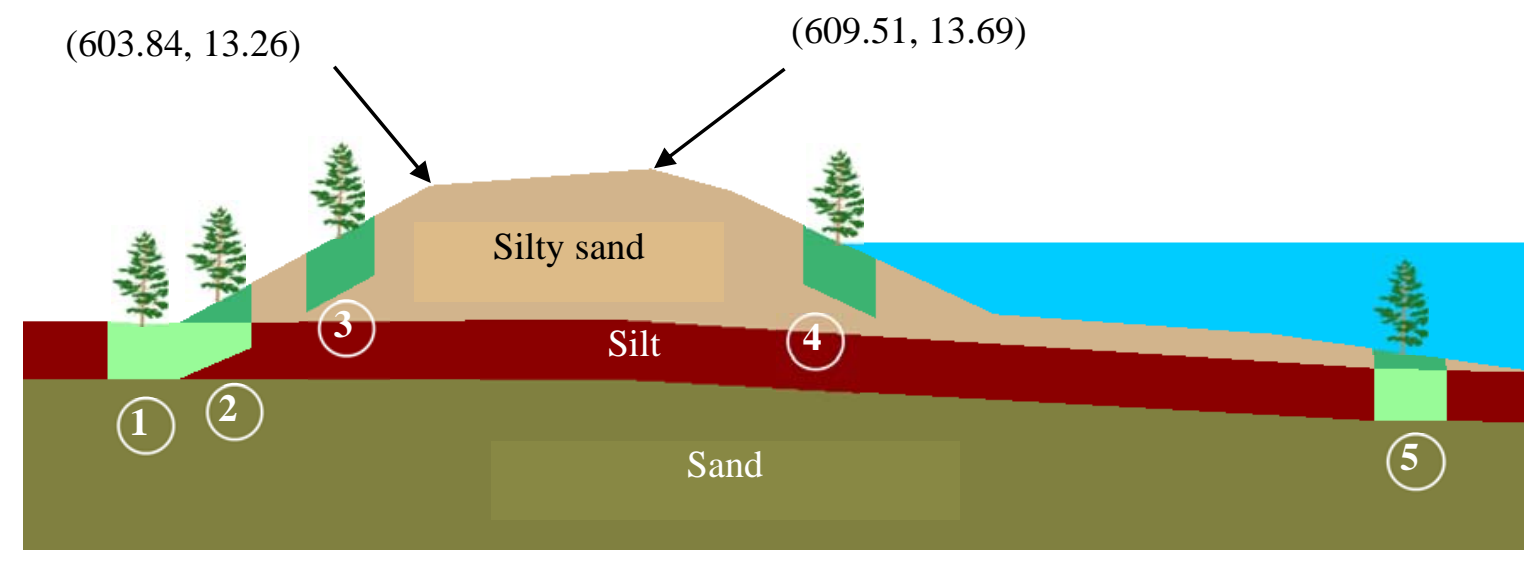

Fig. (11). 2-D cross section of Burlington, WA, levee with root zone placement.

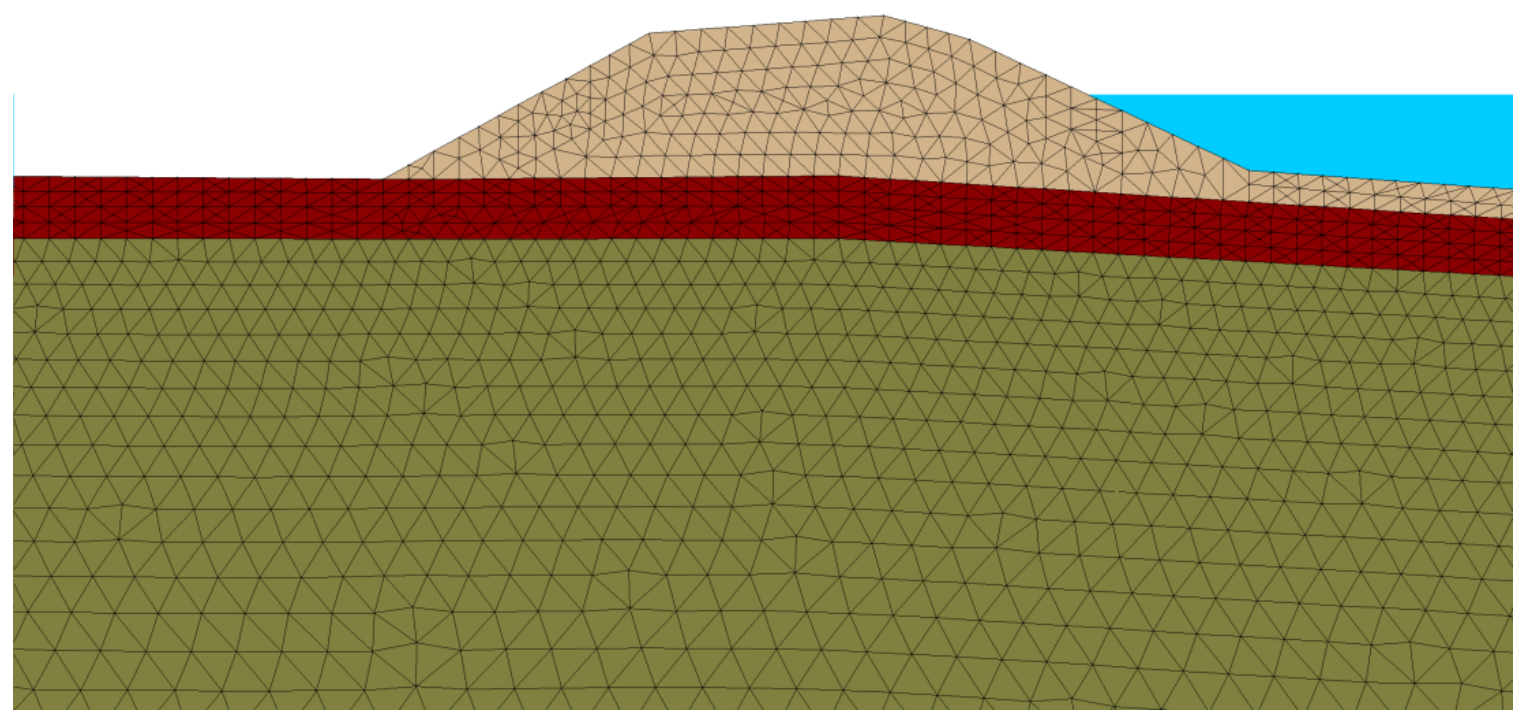

Fig. (12). Portion of 2-D finite element mesh for Burlington, WA, levee.

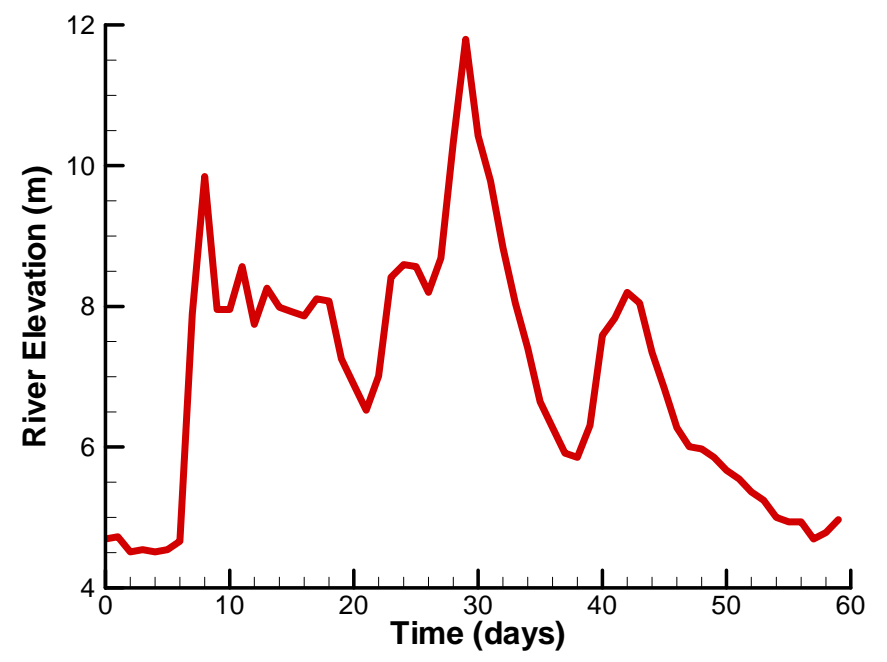

Fig. (13). Hydrograph for the 1995 burlington, WA, flood. 


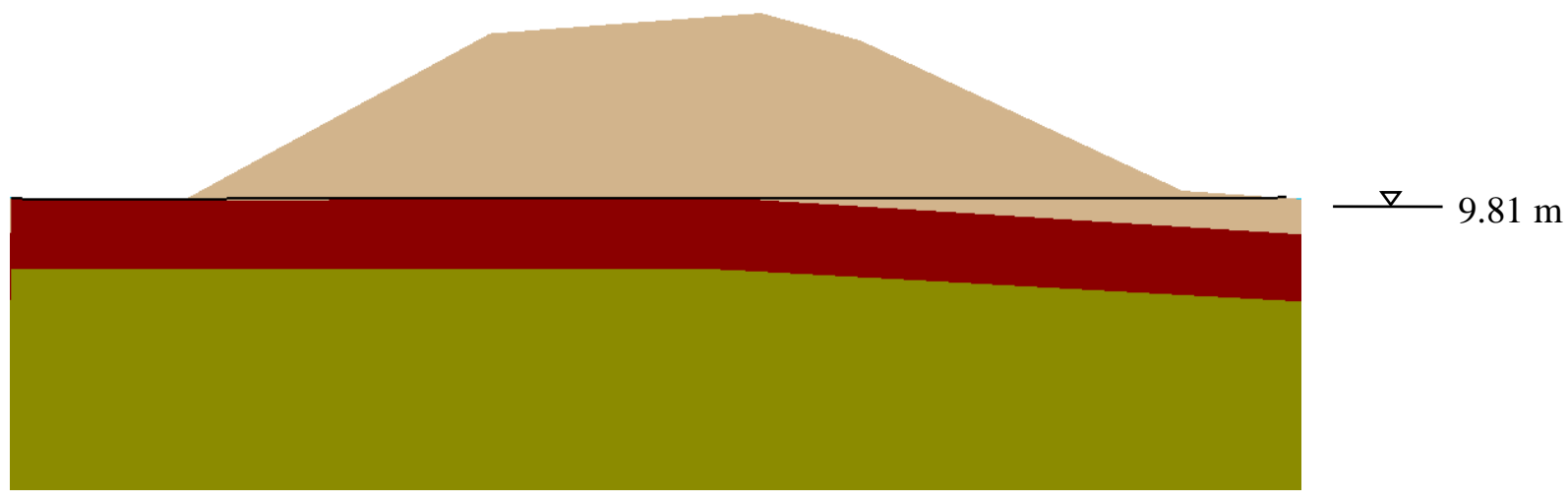

Fig. (14). Initial position of phreatic surface for transient solution for Burlington, WA, levee.

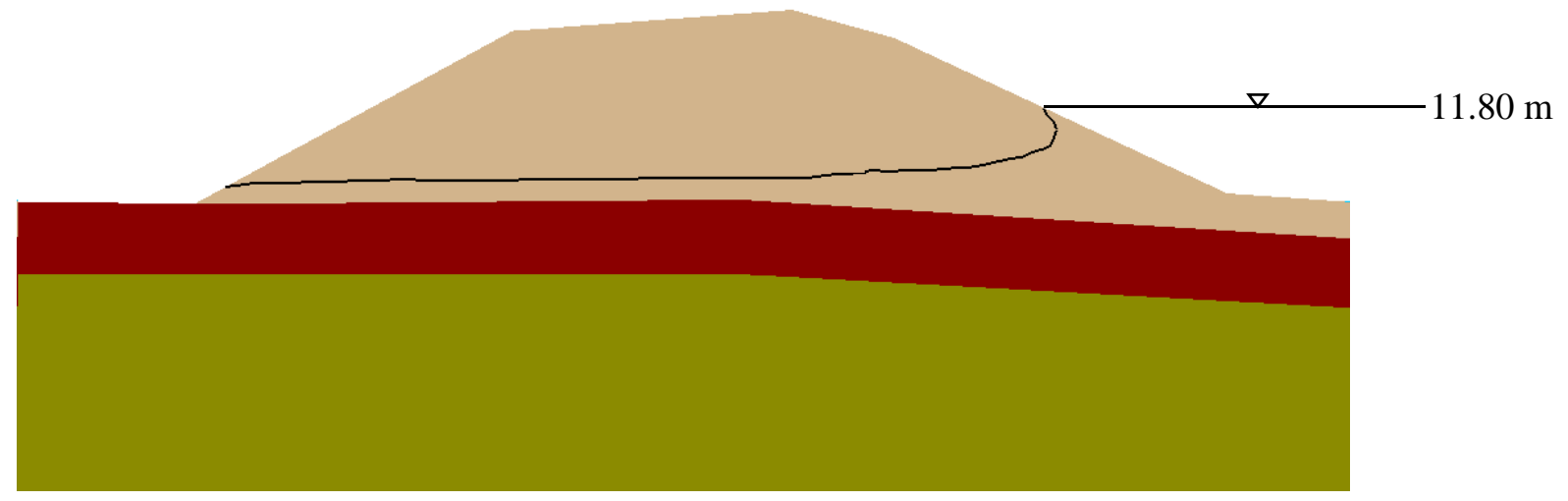

Fig. (15). Portion of phreatic surface at the maximum flood stage from transient solution for Burlington, WA, levee.

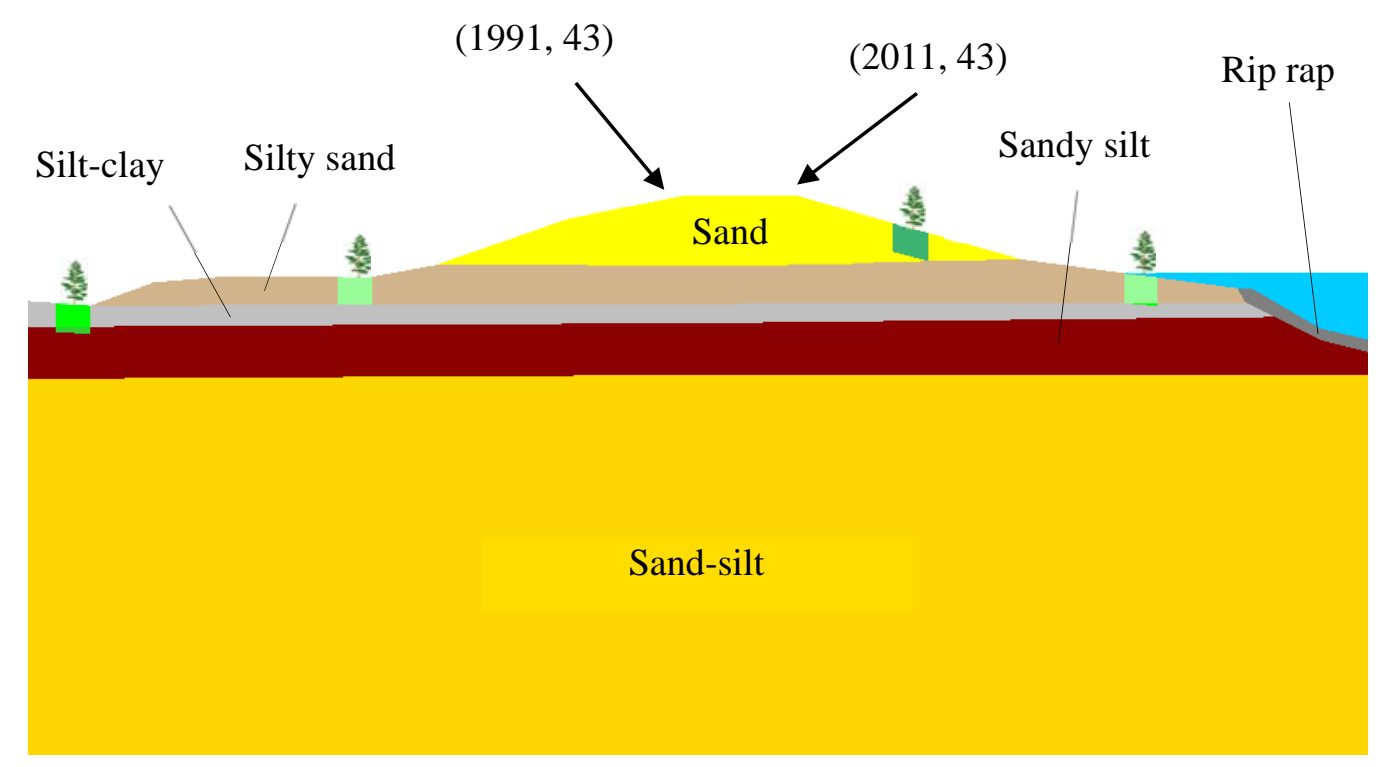

Fig. (16). 2-D cross section of Portland, OR, levee with root zone placement.

Fig. (16). The levee is sand with root zones in the levee, and in the substratums of silty sand and silty clay. Fig. (17) shows a portion of the finite element mesh. The elevation of the river was set to $9.02 \mathrm{~m}$ for the steady-state flow analyses, and the elevation of the water level on the landside was set to $7.62 \mathrm{~m}$ for this cross section. A hydrograph for a Columbia River flood was selected for the transient analysis as shown in Fig. (18). Table 4 gives the hydraulic conductivities used in the numerical analysis.

\subsubsection{Results and Analysis}

Fig. (19) shows the river elevation and phreatic surface at the beginning of the transient run, and Fig. (20) shows this information when the flood has crested at $9.02 \mathrm{~m}$. 


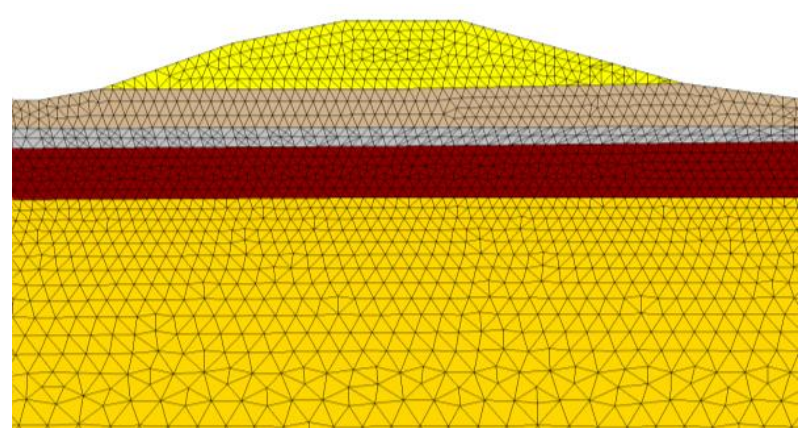

Fig. (17). Portion of finite element mesh for the Portland, OR, levee.

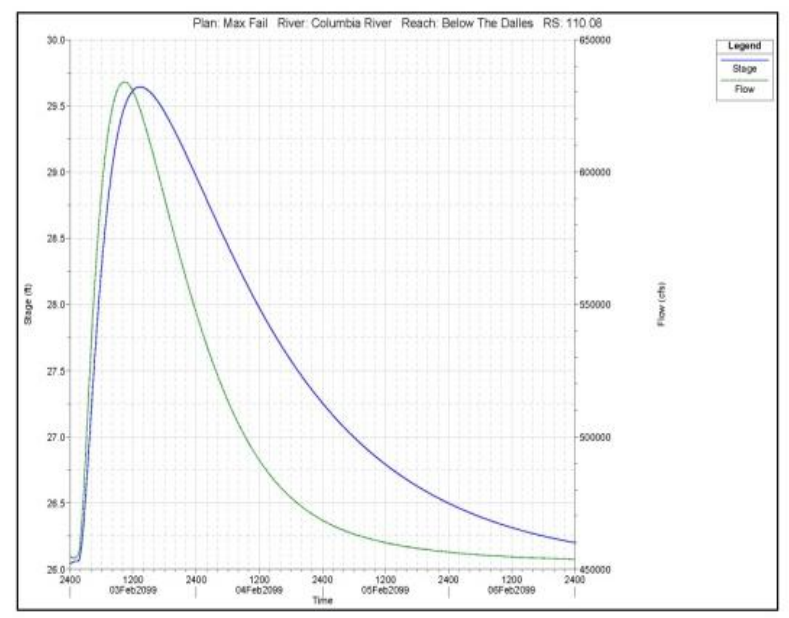

Fig. (18). Hydrograph of the Columbia River, Portland, OR.

Table 4. Original hydraulic conductivities $(\mathrm{cm} / \mathrm{sec})$ for soils without roots used in model for Portland, OR.

\begin{tabular}{|c|c|c|}
\hline Material & $\boldsymbol{k}_{\boldsymbol{H}}(\mathbf{c m} / \mathbf{s e c})$ & $\boldsymbol{k}_{V}(\mathbf{c m} / \mathbf{s e c})$ \\
\hline \hline Sand & $1.94 \times 10^{-2}$ & $9.66 \times 10^{-3}$ \\
\hline Silty sand & $1.94 \times 10^{-3}$ & $9.52 \times 10^{-4}$ \\
\hline Silt-clay & $7.05 \times 10^{-5}$ & $3.52 \times 10^{-5}$ \\
\hline Sandy silt & $1.76 \times 10^{-4}$ & $1.06 \times 10^{-4}$ \\
\hline Sand-silt & $1.94 \times 10^{-3}$ & $9.52 \times 10^{-4}$ \\
\hline Rip rap & 0.645 & 0.645 \\
\hline
\end{tabular}

The results for the Portland levee are similar to the results for the previous two levees. The exit gradient beyond the lower toe increased when $\beta=0.01$, and decreased when $\beta=100$. Exit gradients for the other levee placements were not significantly changed. The exit gradients from the transient analyses were less than the exit gradients from the steady-state analyses. Like in the case of the Burlington levee, the exit gradients mostly exceeded the 0.5 value. Finally, the phreatic surface only slightly lagged as the river rose during the flood.
Table 5. Original hydraulic conductivities $(\mathrm{cm} / \mathrm{sec})$ for soils without roots used in model for Albuquerque, NM.

\begin{tabular}{|c|c|c|}
\hline Material & $\boldsymbol{k}_{\boldsymbol{H}}(\mathbf{c m} / \mathbf{s e c})$ & $\boldsymbol{k}_{V}(\mathbf{c m} / \mathbf{s e c})$ \\
\hline \hline Sand in the levee & $3.00 \times 10^{-3}$ & $3.00 \times 10^{-3}$ \\
\hline Silty sand in the levee & $1.00 \times 10^{-4}$ & $1.00 \times 10^{-4}$ \\
\hline Sandy silt in the blanket & $1.00 \times 10^{-5}$ & $1.00 \times 10^{-5}$ \\
\hline Silty sand in the aquifer & $3.00 \times 10^{-4}$ & $3.00 \times 10^{-4}$ \\
\hline Sand in the aquifer & $6.00 \times 10^{-3}$ & $6.00 \times 10^{-3}$ \\
\hline Toe drain & $1.00 \times 10^{-3}$ & $1.00 \times 10^{-3}$ \\
\hline Pipe drain & $1.00 \times 10^{-2}$ & $1.00 \times 10^{-2}$ \\
\hline
\end{tabular}

\subsection{Albuquerque, NM}

\subsubsection{Finite Element Model}

Fig. (21) shows the geometry, root zone placement, and soil layers for a levee along the Rio Grande River in Albuquerque, NM. The levee is sand with a gravel and sand drain. One root zone has a pipe drain in sandy silt material. The second root zone is in silty sand. Fig. (22) shows a portion of the finite element mesh. The elevation of the river was set to $1520.6 \mathrm{~m}$ and $1521.6 \mathrm{~m}$ for steady-state flow analyses, and the elevation of the water level on the land side was set to $1519.4 \mathrm{~m}$ for this cross section The hydrograph of the 1942 flood as shown in Fig. (23) was selected for the transient analysis. Table $\mathbf{5}$ gives the hydraulic conductivities used in the numerical analysis.

\subsubsection{Results and Analysis}

Table 2 gives exit gradients for the bottom of the dewatered drainage ditch for the three values of $\beta$. Fig. (24) shows the river elevation and phreatic surface at the beginning of the transient run, and Fig. (25) shows this information when the flood has crested at $1520.6 \mathrm{~m}$. The exit gradients at the bottom of the dewatered drainage ditch behaved exactly as the behavior of the exit gradients for a root zone just beyond the toe of the levee in the first three levee systems. The exit gradients for the Albuquerque levee exceeded the 0.5 critical value, which explains why dewatering the drainage ditch is only allowed in special circumstances and certainly not during a flood.

The phreatic surface significantly lagged the rising of the flood stage in the transient solution in this case. This is because the soil where the phreatic surface was rising is less pervious than, for instance, in the Sacramento levee case where the phreatic surface remained the same as the rising water elevation. The speed of the rising flood stage for the Albuquerque levee surpassed the capacity of the phreatic surface to rise. 


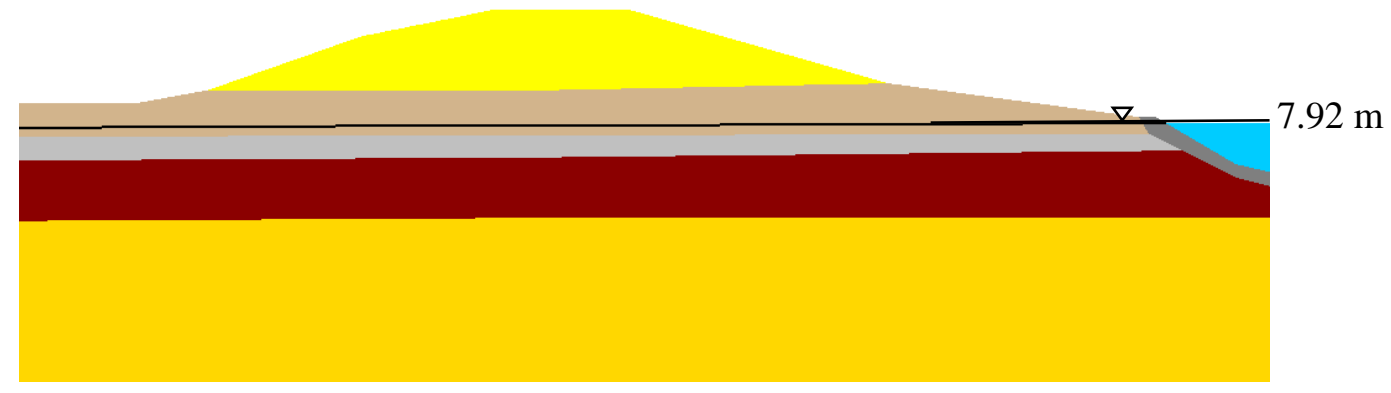

Fig. (19). Initial position of phreatic surface for transient solution for Portland, OR, levee.

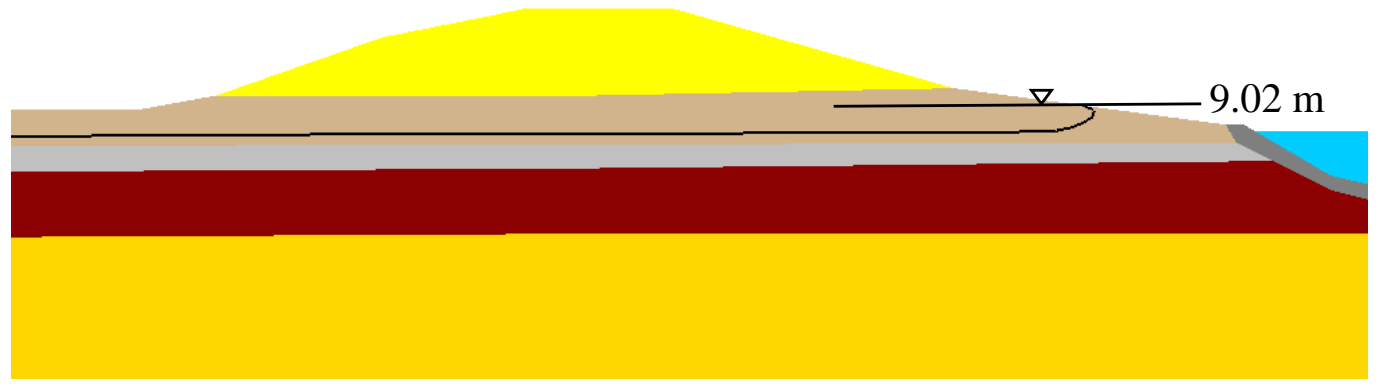

Fig. (20). Portion of phreatic surface at the maximum flood stage from transient solution for Portland, OR, levee.

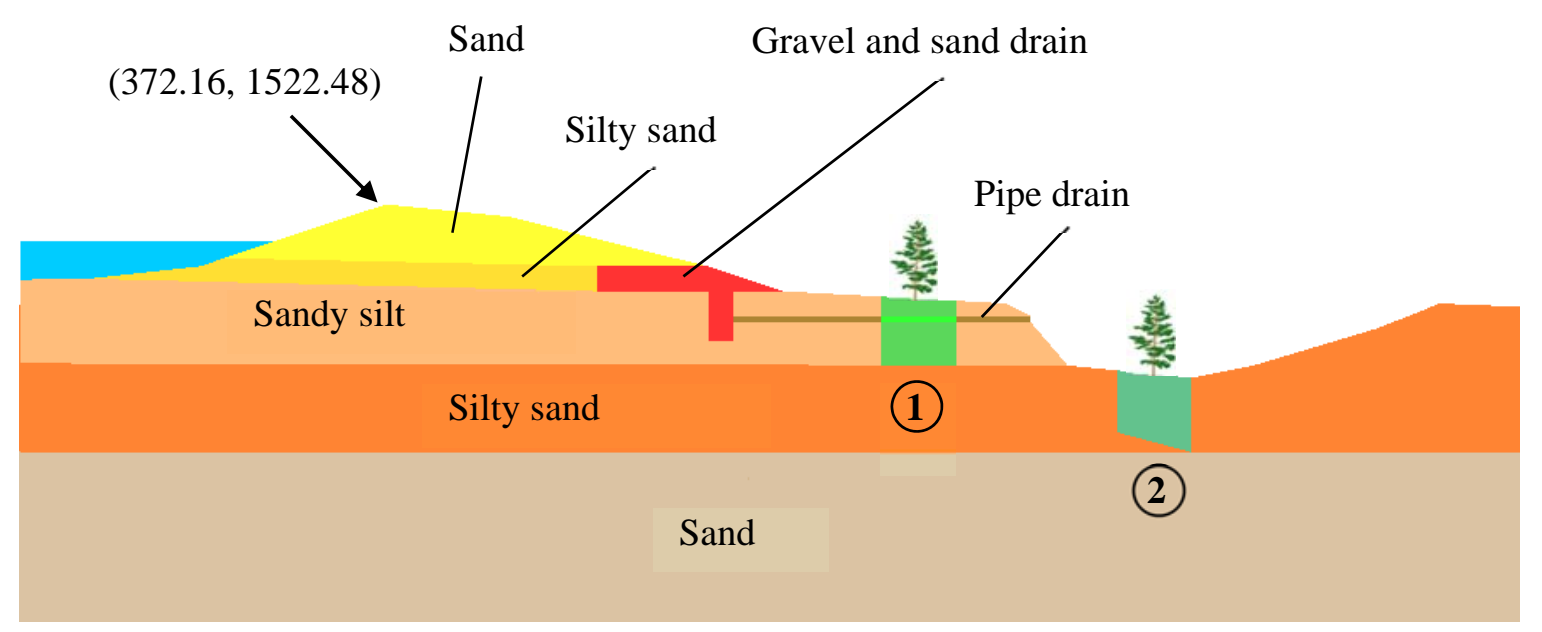

Fig. (21). 2-D cross section of Albuquerque, NM, levee with root zone placement.

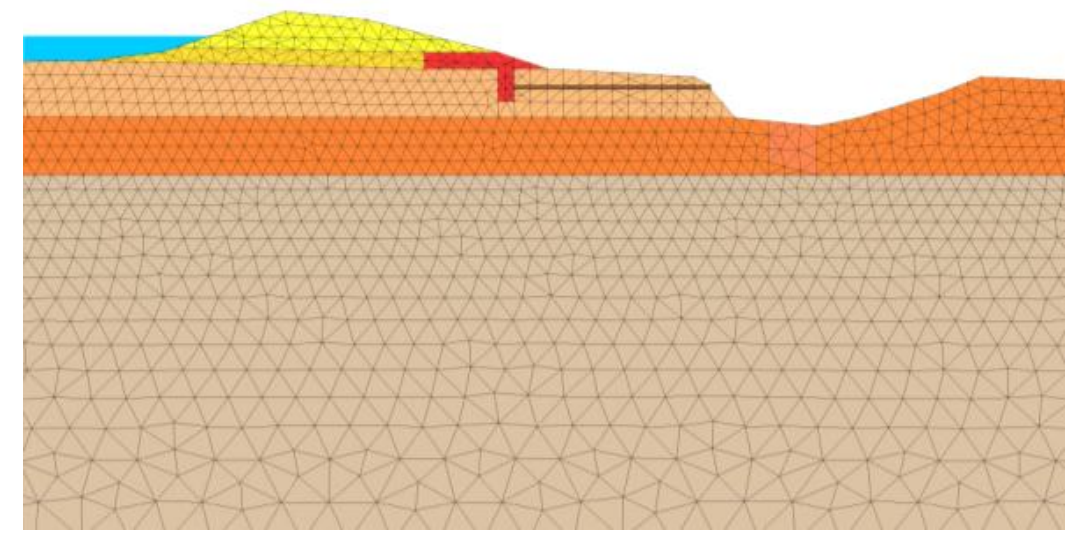

Fig. (22). Portion of 2-D finite element mesh for Albuquerque, NM, levee. 


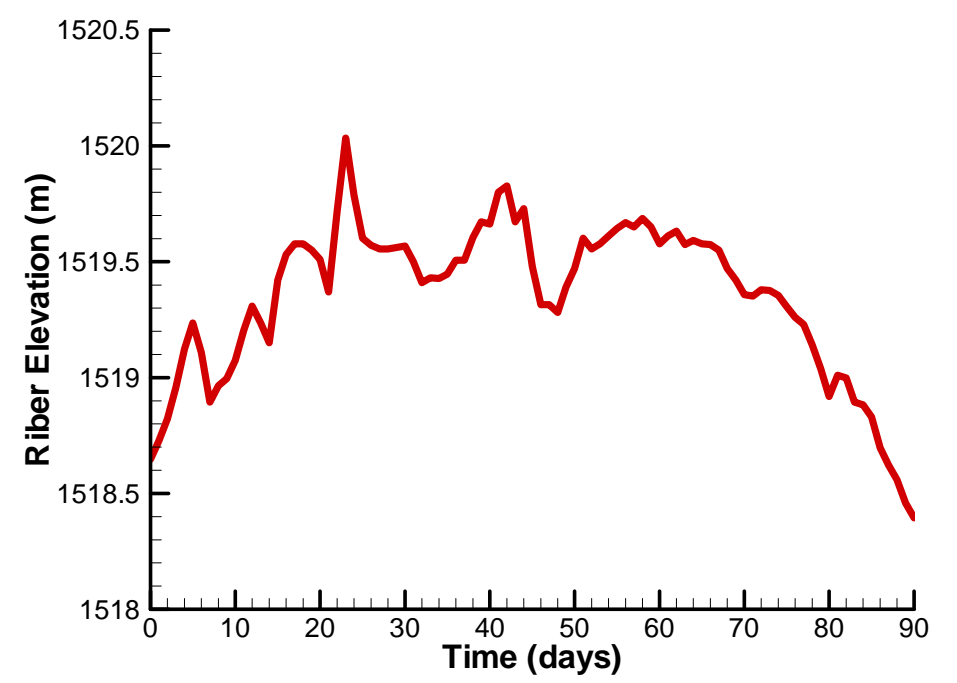

Fig. (23). Hydrograph for the rio grande river for albuquerque, NM, levee.

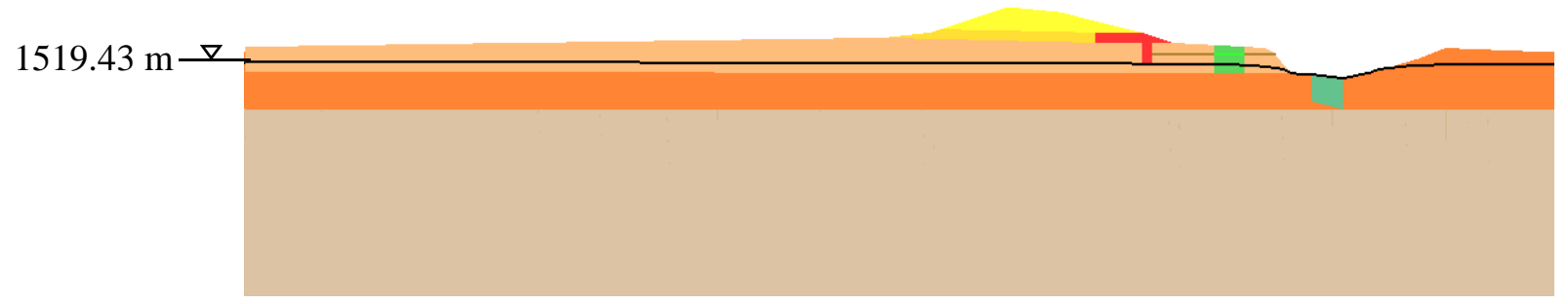

Fig. (24). Initial position of phreatic surface for transient solution for Albuquerque, NM, levee.

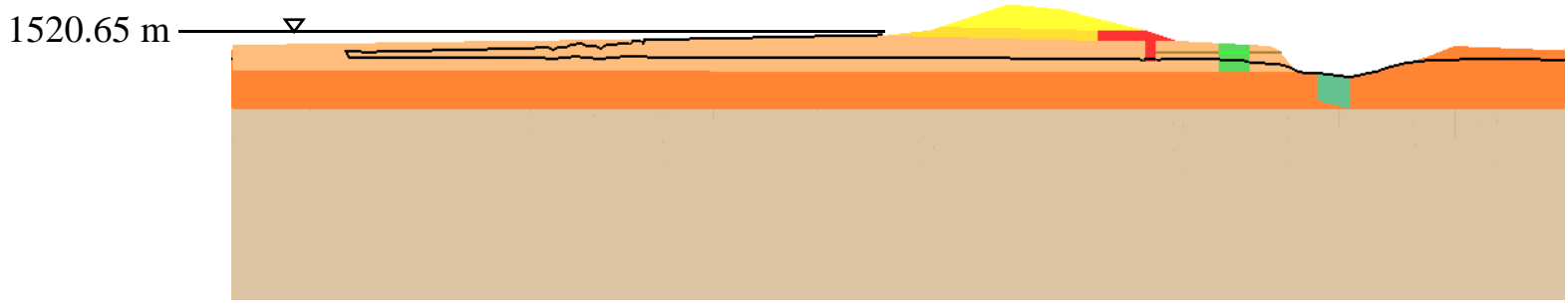

Fig. (25). Portion of phreatic surface at the maximum flood stage from transient solution for Albuquerque, NM, levee.

\section{CONCLUSION}

All the levee systems that were studied yielded completely consistent results. The conclusions from the results are as follows:

- A root zone placed on or just beyond the toe and at the bottom of a dewatered drainage ditch of a levee changed the exit gradient.

- Root zones placed at other points along the levee had little impact on the exit gradient at the toe of the levee or bottom of a dewatered drainage ditch, assuming the absence of long-reaching defects from the roots.

- There is an inverse relationship for a root zone placed just beyond the toe of the levee or below a dewatered drainage ditch. When $\beta$ is increased, the exit gradient just beyond the toe of the levee or at the bottom of the drainage ditch decreases and inversely.
- For a root zone placed on the toe of the levee, when $\beta$ is increased, the exit gradient at the toe decreases. However, when $\beta$ is decreased, the exit gradient often decreases as well.

- The higher the river elevation, the greater the exit gradients.

- The transient solutions yielded lower exit gradients than the steady-state runs.

- The phreatic surface for the transient solution sometimes lagged behind that of the steady-state solution. The amount of lagging depended on the hydraulic condctivity of the soil where the phreatic surface is located.

The hydraulic conductivity constitutes an important property of soil. This study placed root zones at various locations on different levee systems and then determined how 
exit gradients were affected when the hydraulic conductivity of the root zones was changed. This study provides a method to evaluate how changes in hydraulic conductivity affect the exit gradient. In this study, it was assumed that changes in hydraulic conductivity were produced from a root system. In this context, the root system near the toe of the levee produced the greatest fluctuations in exit gradients.

The equivalent hydraulic conductivity in real-world situations can be either increased or decreased to reflect a root system. When the defect has a relatively small radius, the exit gradient remains almost the same, but the defect can be filled with sand from beneath the confining layer. This sand has as much as a hundred times greater hydraulic conductivity than the confining layer, so the seepage velocities can become greater, thus providing the initiation of piping. If other factors such as a cohesionless soil in the confining layer or vulnerability to erosion exist, sand is carried from this lower layer through the vertical defect with the water, and the result is piping and internal erosion of the levee.

This modeling approach could be extended to animal burrows although, in many cases, the geometry and hydrology are significantly modified such that a more sophisticated type of flow model is required.

\section{NOTATION}

\begin{tabular}{|c|c|c|}
\hline$\beta$ & $=$ & $\begin{array}{l}\text { positive parameter with recommended val- } \\
\text { ues of } 0.01 \leq \beta \leq 100\end{array}$ \\
\hline$\Delta \varphi$ & $=$ & increment of total head or potential, $m$ \\
\hline$y$ & $=$ & increment of $\mathrm{y}$ coordinate, $\mathrm{m}$ \\
\hline$s$ & $=$ & density of saturated soil, $\mathrm{nt} / \mathrm{m}^{3}$ \\
\hline$w$ & $=$ & density of water, $n t / \mathrm{m}^{3}$ \\
\hline$i$ & $=$ & exit gradient \\
\hline$i_{c}$ & $=$ & critical exit gradient \\
\hline$k$ & $=$ & hydraulic conductivity, $\mathrm{cm} / \mathrm{sec}$ \\
\hline$k_{\text {orig }}$ & $=$ & $\begin{array}{l}\text { original hydraulic conductivity without a } \\
\text { root, } \mathrm{cm} / \mathrm{sec}\end{array}$ \\
\hline$k_{v e g}$ & $=$ & $\begin{array}{l}\text { modified hydraulic conductivity as a result } \\
\text { of woody vegetation in a root zone, } \mathrm{cm} / \mathrm{sec}\end{array}$ \\
\hline$k_{\text {pipe }}$ & $=$ & hydraulic conductivity of pipe, $\mathrm{cm} / \mathrm{sec}$ \\
\hline$\mu$ & $=$ & viscosity of water, nt-sec/m $\mathrm{m}^{2}$ \\
\hline$p$ & $=$ & pore pressure in soil, $\mathrm{nt} / \mathrm{m}^{2}$ \\
\hline$\varphi$ & $=$ & total head or potential, $\mathrm{m}$ \\
\hline$Q$ & $=$ & water flow per unit time, $\mathrm{m}^{3} / \mathrm{sec}$ \\
\hline$R$ & $=$ & radius of pipe, $\mathrm{cm}$ \\
\hline$R_{i}$ & $=$ & radius of the $i^{t h}$ capillary of a root, $\mathrm{cm}$ \\
\hline$k_{\text {root }, L}$ & $=$ & $\begin{array}{l}\text { longitudinal hydraulic conductivity of a root, } \\
\mathrm{cm} / \mathrm{sec}\end{array}$ \\
\hline$o t, T$ & $=$ & $\begin{array}{l}\text { transverse hydraulic conductivity of a root, } \\
\mathrm{cm} / \mathrm{sec}\end{array}$ \\
\hline
\end{tabular}

$\begin{array}{lll}k_{1} & = & \text { hydraulic conductivity of soil type } \\ k_{2} & = & \text { hydraulic conductivity of soil type } \\ \theta_{1} & = & \begin{array}{l}\text { angle an equipotential line make } \\ \text { interface between two soils havin } \\ \text { conductivities, } k_{1} \text { and } k_{2}, \text { on the }\end{array} \\ & & \text { rad }\end{array}$

\section{CONFLICT OF INTEREST}

The authors confirm that this article content has no conflict of interest.

\section{ACKNOWLEDGEMENTS}

This work was supported in part by a grant of computer time from the Department of Defense High Performance Computing Modernization Program. Permission to publish was granted by the Director, Geotechnical and Structures Laboratory.

\section{REFERENCES}

[1] U.S. Army Corps of Engineers. Design guidance for levee underseepage. ETL 1110-2-569. Washington, DC. 2005.

[2] Tulik M, Marciszewska K. Plant and soil as hydraulics systems. In: Elango M. Eds. Hydraulic conductivity - issues, determination and applications, InTech, Rijeka, Croatia 2011; pp. 97-100.

[3] R-SWMS. Root-Soil Water Modeling System. http://www2.fzjuelich.de/icg/icg-4/index.php?index=950. 2014.

[4] Simunek J, Huang K, Van Genuchten M Th. The SWMS_3D code for simulating water flow and solute transport in three-dimensional variably-saturated media. Version 1.0, research report number 139, U.S. Salinity Laboratory, Agricultural Research Service, Department of Agriculture, Riverside, CA. 1995.

[5] Doussan C, Pages L, Vercambre G. Modeling of the hydraulic architecture of root systems: an integrated approach to water absorption-model description. Annals of Botany 1998; 81: 213 -23.

[6] Somma F, Hopmans J, Clausnitzer V. Transient three-dimensional modeling of soil water and solute transport with simultaneous root growth, root water and nutrient uptake. Plant Soil 1998; 202: 28193.

[7] Simunek J, van Genuchten M. Th, Sejna M. The HYDRUS software package for simulating the two- and three-dimensional movement of water, heat, and multiple solutes in variably- saturated media. Technical manual, version 1.0, University of California, Riverside, CA. 2006.

[8] Corcoran M, Peters J, Dunbar J, Llopis J, Tracy F, Wibowo J, Simms J, Kees C, McKay S, Fischenich J, Farthing M, Glynn M, Robbins B, Strange R, Schultz M, Clarke J, Berry T, Little C, Lee L. Initial research into the effects of woody vegetation on levees, volume I of IV: project overview, volume II of IV: field data collection, volume III of IV: numerical model simulation, volume IV 
of IV: summary of results and conclusions. U.S. Army Engineer Research and Development Center, Vicksburg, MS. 2011.

[9] Sutera S, Skalak R. The history of Poiseuille's law. Ann Rev Fluid Mech 1993; 25: 1-19.

[10] Groundwater Modeling System. http://chl.erdc.usace.army.mil/gms. 2014.
[11] Tracy F. User's guide for a plane and axisymmetric finite element program for steady-state seepage problems. Instruction report K83-4. U.S. Army Engineer Waterways Experiment Station, Vicksburg, MS. 1983.

Received: August 23, 2014

Revised: October 20, 2014

Accepted: October 21, 2014

(C) Tracy and Corcoran; Licensee Bentham Open.

This is an open access article licensed under the terms of the Creative Commons Attribution Non-Commercial License (http://creativecommons.org/licenses/by-nc/3.0/) which permits unrestricted, non-commercial use, distribution and reproduction in any medium, provided the work is properly cited. 